\title{
CZECH REPUBLIC VS. EU-27: ECONOMIC LEVEL, HEALTH CARE AND POPULATION HEALTH
}

\author{
Oldřich Hájek, Pavel Grebeníček, Boris Popesko, Šárka Hrabinová \\ Faculty of Management and Economics, Tomas Bata University in Zlín, Zlín, Czech Republic
}

\begin{abstract}
SUMMARY
This paper focuses on the improvement of the health characteristics in European countries including the life expectancy of their inhabitants. The primary objective is to describe, compare and analyze the status and development in the Czech Republic and other countries of the European Union in terms of the key health care indicators and population health status in relation to the economy related indicators the authors have chosen. The secondary objective is to verify the hypothesis which states that the health status of the population represented by the indicator of life expectancy is closely related to the economic level of individual countries as well as to the amount of total expenditure on health care. Based on the results of the analysis we can conclude that the Czech Republic balances on the border of the group of countries with average values of indicators and the group with poorer values. The results also suggest relatively strong ties between the economic level and health status of the population represented by life expectancy.
\end{abstract}

Key words: health, life expectancy, economic level, health care, Czech Republic, European Union

Address for correspondence: Oldrïch Hájek, Mostní 5139, 76001 Zlín, Czech Republic. E-mail: hajek@fame.utb.cz

\section{INTRODUCTION}

The issues of aging of not only the European but also other populations and the impact of this matter on functioning of social and health care systems in individual countries have become a subject of an ongoing academic and political debate during the last years and decades. On one hand, the fertility rate decreases, on the other hand we can observe improvement in indicators of health status of the European population including lengthening of the life expectancy. This paper will focus on the improvement of overall status of health in the European population and will highlight some interesting facts and connections, especially the question of improving health care and its effect on the health status of population.

The phenomenon of lengthening life expectancy, declining mortality and general improvement of the health status of population in more developed countries became focal point of many authors who examine the impact of better health care and higher health expenditure on the increase in life expectancy.

In their paper, Catalano and Frank (1) deal with the question of improved health care (e.g. using of new types of drugs, new therapies or new diagnostic devices and methods) (2) and its contribution to decreasing mortality. They note considerable inconsistencies in used methods when examining these matters and some general difficulties in proving the dependency of better health care and increased longevity. The problem may also be sometimes caused by the examined data themselves or by their definition, acquisition, calculation or measurement $(3,4)$.

Based on the research conducted in the US population, Bunker estimates that approximately half the increase in life expectancy in the second half of the 20th century is due to improved health care (5). Cutler et al. examined increasing medical costs in the US in the period 1960-2000 and their influence on prolonging the life expectancy in four age categories. The contribution of the health care factor to the increased life expectancy was also estimated at $50 \%$ (6). McKee shows on several examples that a good level of health care helps to improve the general health status of the population and positively influences the life expectancy (7).

Ginter and Simko examined differences among the outcomes of the health care systems and the health care expenditure in the US and the European Union (8). The authors point out the fact that several times higher expenditure in the US does not necessarily result in increased life expectancy which is actually higher in the EU countries (9-11). Other authors deal with matter of increasing health care expenditure, its efficient allocation and possible positive effects on health outcomes (12-14). Gulliford et al. examined the dependence of health status of the British population on accessibility and structure of the primary health care represented by accessibility of the general practitioners. According to the authors, the mutual influence is rather weak (15). On the contrary, $\mathrm{Gu}$ et al. focused on older Chinese population and concluded that good accessibility of health care in childhood and adulthood ultimately increases the life expectancy of the population and improves the quality of life (although it is not the only significant factor) (16). Similar conclusions on accessibility of the health care and higher life expectancy were also made by Alonso et al. (17). Ginter et al. identified health care factors that influence the increase in life expectancy on the example of Slovakia and the Czech Republic. Authors argue that the increase in health care quality is achieved by higher spending on health care services and health education (18). 
Improved health care does not only change life expectancy but also the quality of life (smooth functioning in society, physical mobility, mental health or absence of problems associated with pain). The question is whether the effects of modern health care should be viewed more in terms of life quality rather than in terms of increase in life expectancy alone (19). Some authors created models that try to determine the effect of the improved health care on the increase in life expectancy or on the quality of life (20). Another group of authors place the emphasis on broader social determinants of health (21-29). Among those advances in nutrition, housing, hygiene, working conditions or life style are often mentioned. Adams et al. introduced statistical method which can be used to investigate association between socio-economic status and health status of population (30). Similarly, Bauer et al. created a model of indicators which may be used to monitor the development of health under the influence of different environment and individual determinants (31). Möller et al. introduced three different approaches to the evaluation of the health care systems (32). Some authors added the aspect of politics to the above mentioned approaches. The infant mortality rate or life expectancy indicators in different OECD countries were assessed in the context of political traditions and ideologies of the governing parties (33).

The primary objective of this paper is to describe, compare and analyze the status and the development in the Czech Republic and other countries of the European Union in terms of key health care and population health indicators in relation to the economic indicators the authors have chosen (e.g. GDP per capita). The secondary objective is to verify the authors' hypothesis which states that the health status of the population represented by the life expectancy indicator or the indicator of standardized death rate is closely related to the economic level of individual countries as well as to the amount of total expenditure on health care.

\section{METHODS}

For the purposes of this survey, the authors first created a system of 8 indicators in three different thematic categories. The annual values of these indicators for individual countries are the database which can be further used for description, comparison and analysis in accordance with the objectives of the paper. Thematic categories were chosen in accordance with the previously stated hypothesis so that the authors can determine a possible association among the economic level, provided health services and the health status of the population. The available indicators were chosen so that the status of different countries in the thematic categories can be adequately described despite the limited number of such indicators. The list of analyzed indicators and their division into thematic categories is shown in Table 1.

For better understanding, a few notes about the following indicators. To be able to compare different countries, the real GDP per capita is indicated in so called international dollars - PPP\$ (it includes purchasing power parity of the respective currencies). The total health expenditure per capita indicator includes a sum of general government expenditure and private expenditure on health. The units are also international dollars - PPP\$. The total health expenditure as $\%$ of GDP indicator also includes public and private expenditure. The acute care hospital beds per 100,000 inhabitants include only bed in acute hospitals and short hospital stays up to 18 days. The physicians per 100,000 inhabitants indicator reflects the number of physicians at the end of the year and includes all active physicians working in public or private health services. The nurses per 100,000 inhabitants indicator indicates the number of nurses at the end of the year and includes only active nurses. Life expectancy at birth (LE) is one of the basic demographic indicators and reflects the average number of years a person may expect to live based on age-specific mortality data (8). For the purposes of this paper, the standardized death rate (SDR) per 100,000 inhabitants includes mortality of all cause and all ages.

The data was obtained from the Health for All Database that is maintained by the Regional Office for Europe of the World Health Organization (WHO) (34). Another source of data was the Eurostat Statistics Database (35).

The data was collected for the reference period of 1990-2009. However, comparison and use in graphical outputs made the authors use a shorter period of 1995-2008 because of availability and completeness of the required statistical data.

In accordance with the objective set above, the analysis was conducted using the indicators of 27 countries that now constitute the European Union (so called EU-27). Apart from the Czech Republic, these are: Austria, Belgium, Bulgaria, Cyprus, Denmark, Estonia, Finland, France, Germany, Greece, Hungary, Ireland, Italy, Latvia, Lithuania, Luxembourg, Malta, the Netherlands, Poland, Portugal, Romania, Slovakia, Slovenia, Spain, Sweden and the United Kingdom.

The evaluation is based on the essential methods of descriptive statistics. The strength of mutual dependency (or correlation) of the indicators was evaluated and assessed by the correlation

Table 1. System of evaluated indicators

\begin{tabular}{|l|l|}
\hline Thematic categories of indicators & Indicators \\
\hline \multirow{4}{*}{ A. Economic level indicators } & A.1. Gross domestic product (GDP) per capita \\
\cline { 2 - 2 } & A.2. Total health expenditure per capita \\
\cline { 2 - 2 } & A.3. Total health expenditure as $\%$ of GDP \\
\hline \multirow{3}{*}{ B. Health care indicators } & B.1. Acute care hospital beds per 100,000 inhabitants \\
\cline { 2 - 2 } & B.2. Physicians per 100,000 inhabitants \\
\cline { 2 - 2 } & B.3. Nurses per 100,000 inhabitants \\
\hline \multirow{2}{*}{ C. Health status of population indicators } & C.1. Life expectancy at birth \\
\cline { 2 - 2 } & C.2. Standardized death rate per 100,000 inhabitants \\
\hline
\end{tabular}


coefficient. The data of the whole reference period was used in this calculation. The spatial context is expressed graphically using cartographic methods in the GIS environment.

For clearer evaluation and comparison, the annual values of indicators for each country were divided evenly into three equal groups by calculating the lower and the upper tertile (a tertile divides a set of statistical data into thirds). The group of compared countries was, according to the value of respective indicator, divided into a subset of 9 countries with improved value of an indicator (these countries are labeled by value 1 in the Tables and Figures), 9 countries with average value of an indicator (labeled by value 2) and 9 countries with poorer value of an indicator (labeled by value 3 ). By analogy, this distribution was also used for the indicator nurses per 100,000 inhabitants where no complete data was available for Belgium and Greece. This distribution is used in the whole paper including Tables and graphic outputs.

\section{RESULTS}

Figure 1 focuses on the GDP per capita indicator. The Czech Republic (PPP\$ 24,769 per capita) ranks at the very end of the group of countries with average value of this indicator, on the 18th position out of 27 compared countries. Luxembourg (PPP\$ 83,759 per capita), Malta (PPP\$ 53,527 per capita) and Cyprus (PPP\$ 49,423 per capita) reached the highest values. Bulgaria (PPP\$ 12,394 per capita), Romania (PPP\$ 14,297 per capita) and Latvia (PPP\$ 17,148 per capita) are on the opposite end of the scale with the worst values. The Czech Republic recorded increase in the value of this indicator by $+93 \%$ in the reference period 1995-2008. It is slightly above the EU-27 average. The highest increase was recorded in Estonia, Lithuania and Latvia. The smallest increase of this indicator was recorded in Italy, Malta and Belgium.

Figure 2 compares countries' total health expenditure per capita. The Czech Republic records a value of PPP\$ 1,684 per capita and among the former Eastern Bloc countries occupies rather low rank (the 20th position). The leading is Luxembourg (PPP\$ 6,047 per capita), followed by Malta (PPP\$ 4,039 per capita) and Austria (PPP\$ 3,836 per capita). The last positions are occupied by Romania (PPP\$ 665 per capita), Bulgaria (PPP\$ 910 per capita) and Latvia (PPP\$ 1,112 per capita). The data of the Czech Republic is confirmed by the indicator of total health expenditure as \% of GDP. The Czech Republic ranks 21st with $6.8 \%$ share of health expenditure on GDP. The highest share was noted in France (11.1\%), Germany (10.4\%), Austria (10.1\%) and Portugal (10.1\%). The end of the spectrum is again represented by Romania (4.7\%), also by Estonia (5.9\%) and Lithuania (6.2\%). The position of Luxembourg is rather interesting. Even though the share of the health expenditure on GDP is below the average, the values indicating total expenditure per capita are by far the highest. The opposite example presents Portugal which has relatively low expenditure per capita but when measuring the share of the health expenditure of GDP, the country has the highest ranking. As for the dynamics and change of these indicators between 1995 and 2008 in European comparison, poorer values are generally observed in the Czech Republic. Total health expenditure per capita increased by $87 \%$. The smallest increase was observed in Germany, Austria and France. The largest change was reported by Lithuania, Latvia and Romania. As for the share of the health expenditure of GDP, the Czech Republic even recorded a decline of -0.2 percentage point (of all the other countries only Estonia recorded a decrease). On the contrary, the highest positive change was observed in Portugal ( +2.3 percentage point) and the United Kingdom ( +2.2 percentage point).

Table 2 presents values of the health care indicators per 100,000 inhabitants for each EU country. The number of acute hospital beds per 100,000 inhabitants in the Czech Republic is above an average of the compared countries. With 507.5 beds per 100,000 inhabitants, the Czech Republic ranks fourth after Austria, Germany and Latvia. The lowest values were observed in the North European countries - Finland and Sweden. The Czech Republic reported 354.0 physicians per 100,000 and is slightly

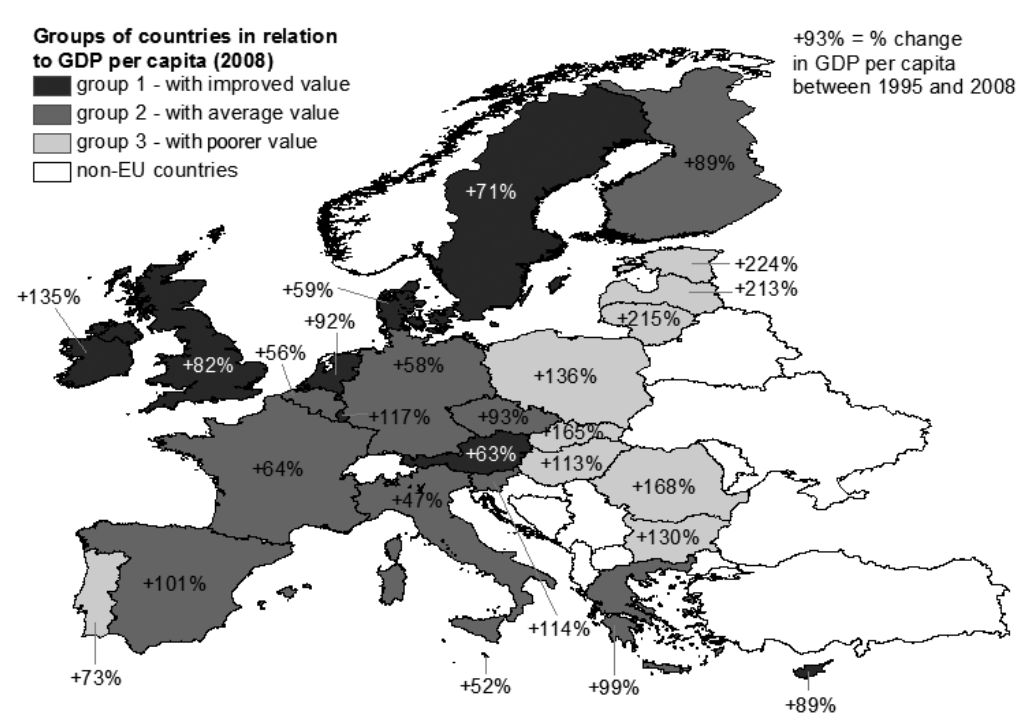

Fig. 1. GDP per capita in EU-27. 


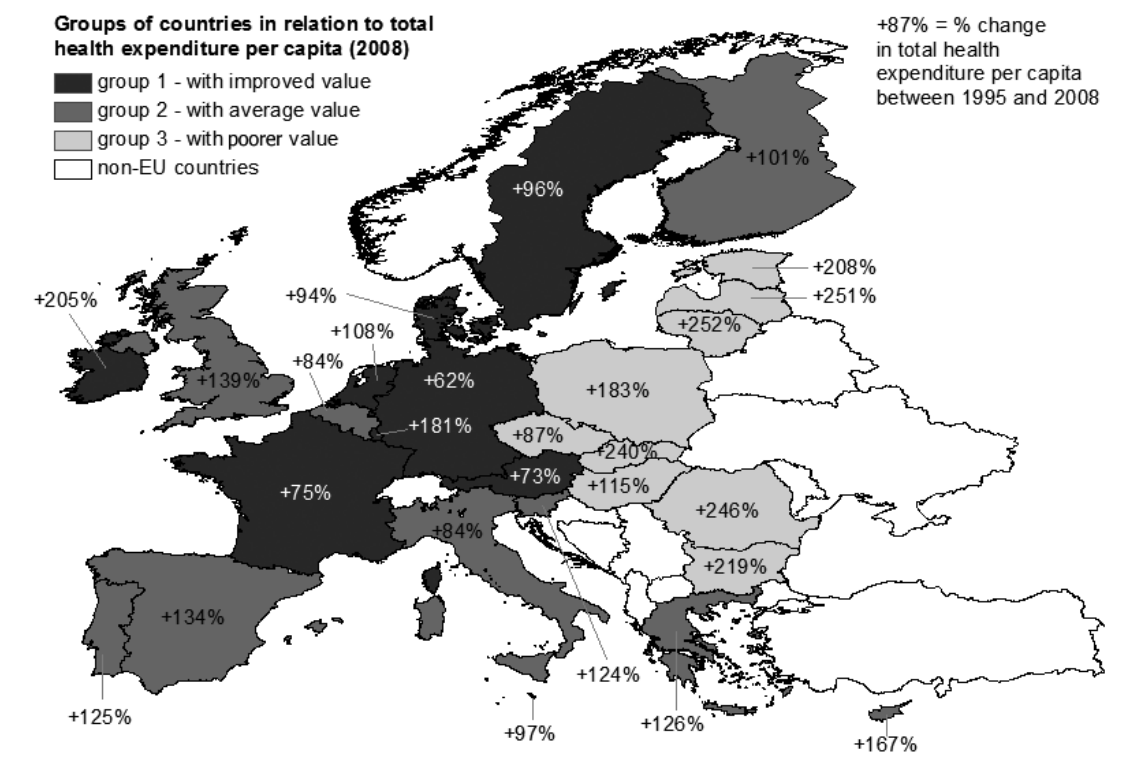

Fig. 2. Total health expenditure per capita in EU-27.

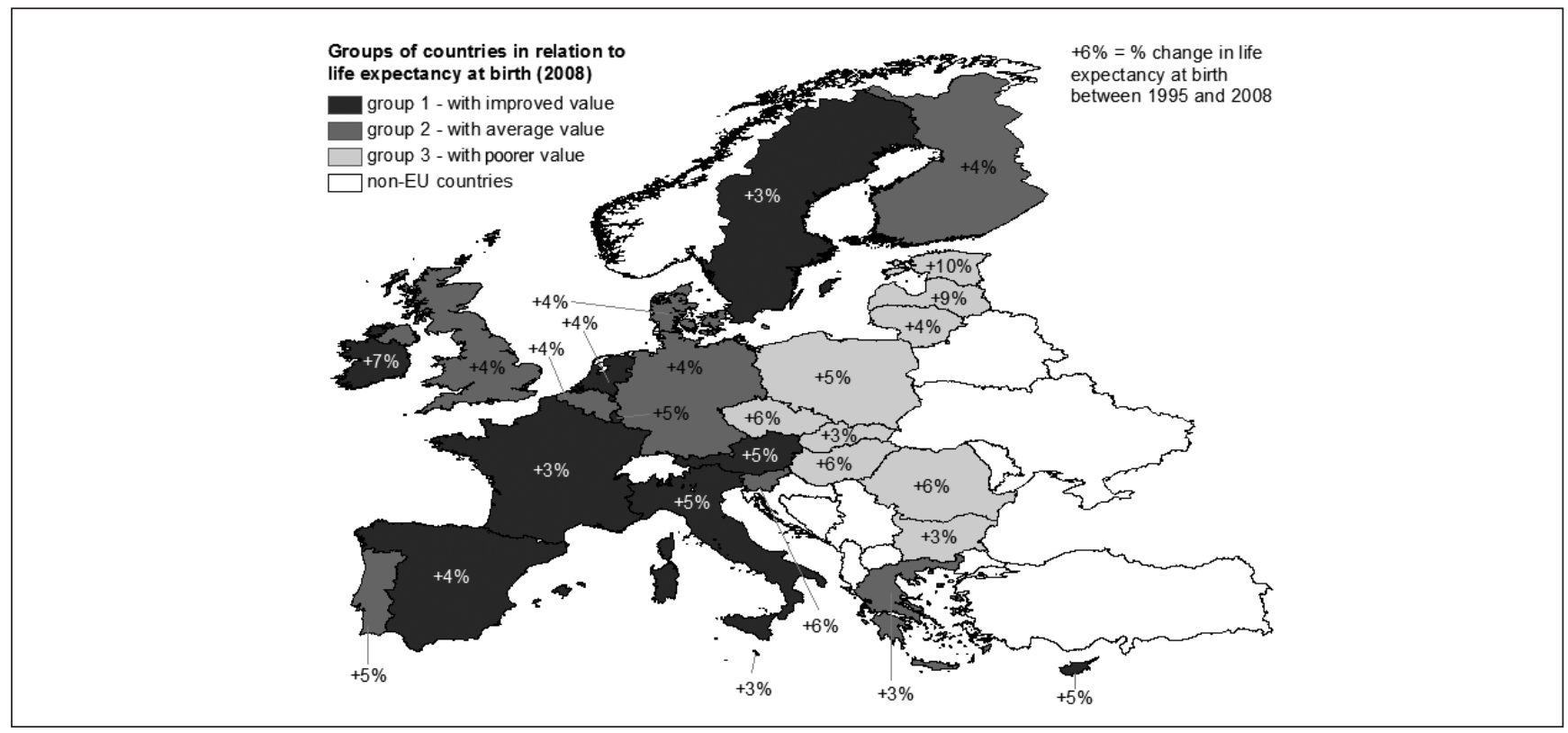

Fig. 3. Life expectancy at birth in EU-27.

above the average of the compared countries. The highest values were observed in Greece and Austria, on the opposite part of the spectrum are Poland and Romania. The last indicator monitored by the authors is the number of nurses per 100,000 inhabitants, with the Czech Republic belonging to the average group of countries (indicator value is 793.6). The highest values were recorded in Finland and Denmark, lowest in Spain and Bulgaria. We can summarize these finding by stating that the Czech Republic is an average as for the number of medical personnel and recorded increased values in the number of acute hospital beds (Table 3).

Figure 3 presents comparison of the life expectancy at birth for EU-27 countries. The Czech Republic recorded 77.4 years (74.2 years in men, 80.6 in women) and ranks 19th. The highest expectancies were recorded in Italy (81.9 years), Spain (81.5) and
France (81.4). The lowest ranking countries are Lithuania (72.1 years), Latvia (72.5 years) and Bulgaria (73.4 years). Development of this indicator between 1995 and 2008 is quite positive in the Czech Republic as it increased by $5.6 \%$. The biggest change in this reference period was registered in Estonia, Latvia and Ireland. The smallest positive changes can be seen in Sweden, Greece and Malta.

The last indicator, standardized death rate per 100,000 inhabitants, essentially eliminates the influence of age structure of the population of the compared countries. With the value of 746.1 per 100,000 inhabitants, the Czech Republic ranks among the group of countries with poorer values occupying the 19th position. This observation is further confirmed by more in-depth examination of this indicator. It applies to both men and women and to majority of monitored causes of death. The most favourable values were 
Table 2. Health care indicators in 2008, per 100,000 inhabitants

\begin{tabular}{|l|c|c|c|}
\hline & $\begin{array}{c}\text { Acute hospital } \\
\text { beds }\end{array}$ & Physicians & Nurses \\
\hline Austria & 563.5 & 459.6 & 751.6 \\
\hline Belgium & 432.8 & 298.4 & N/A \\
\hline Bulgaria & 498.7 & 360.5 & 423.9 \\
\hline Cyprus & 349.4 & 287.0 & 467.8 \\
\hline Czech Republic & 507.5 & 354.0 & 793.6 \\
\hline Denmark & 298.5 & $341.9{ }^{*}$ & $1,428$. * $^{*}$ \\
\hline Estonia & 385.1 & 334.9 & 640.2 \\
\hline Finland & 190.8 & 272.1 & $1,547.2^{*}$ \\
\hline France & 360.0 & 344.2 & 816.9 \\
\hline Germany & 565.4 & 355.7 & $1,068.0$ \\
\hline Greece & 395.3 & 601.1 & $\mathrm{~N} / \mathrm{A}$ \\
\hline Hungary & 411.1 & 309.1 & 615.5 \\
\hline Ireland & $265 . *^{*}$ & 311.2 & $1,551.6$ \\
\hline Italy & 299.9 & 412.5 & 619.5 \\
\hline Latvia & 517.2 & 310.7 & 533.5 \\
\hline Lithuania & 504.7 & 369.6 & 711.2 \\
\hline Luxembourg & 432.2 & $284.4^{*}$ & $1,094$. * $^{*}$ \\
\hline Malta & 276.9 & 304.1 & 642.5 \\
\hline Netherlands & 285.6 & $370.0 *$ & $1,051.2^{*}$ \\
\hline Poland & 441.2 & 216.2 & 519.3 \\
\hline Portugal & 276.4 & 366.5 & 533.9 \\
\hline Romania & 450.9 & 221.4 & 552.1 \\
\hline Slovakia & 487.2 & $300.1{ }^{*}$ & 624.7 \\
\hline Slovenia & 379.9 & 238.0 & 780.8 \\
\hline Spain & 249.1 & 349.8 & 462.4 \\
\hline Sweden & $218 . *^{*}$ & $357.9{ }^{*}$ & $1,083.4^{*}$ \\
\hline United Kingdom & 269.4 & 256.8 & 938.4 \\
\hline
\end{tabular}

Fields marked * are based on the latest available statistic data from 2005-2007.

documented in Italy (502.9), Spain (519.7) and France (522.5). The lowest ranking positions belong to Lithuania (1,033.2), Latvia $(1,006.2)$ and Bulgaria (995.4). As for the change of SDR in 1995-2008 period, the Czech Republic recorded a very positive decrease by $-27 \%$. The largest drop was noted in Ireland (-35\%), the smallest in Lithuania (-13\%).

Table 3 summarizes the classification of all countries and all indicators to one of three previously specified categories. The Czech Republic ranks among countries with an average or poorer values in almost all analyzed indicators.

Table 4 shows calculated values of the correlation coefficient for specified variables. We can see a large direct dependence between GDP per capita and total health expenditure per capita $(+0.94)$. The results also suggest relatively strong association between economic related indicators (GDP per capita and total health expenditure per capita) and indicators of health status of population. The value of the correlation coefficient for the first economy related indicator is +0.76 in connection with the life expectancy (direct relation) and -0.76 (indirect relation) in connection with
Table 3. Overview of the ranking of the countries according to values of indicators in 2008

\begin{tabular}{|l|c|c|c|c|c|c|c|c|}
\hline & A.1. & A.2. & A.3. & B.1. & B.2. & B.3. & C.1. & C.2. \\
\hline Austria & 1 & 1 & 1 & 1 & 1 & 2 & 1 & 1 \\
\hline Belgium & 2 & 2 & 1 & 2 & 3 & N/A & 2 & 2 \\
\hline Bulgaria & 3 & 3 & 3 & 1 & 1 & 3 & 3 & 3 \\
\hline Cyprus & 1 & 2 & 3 & 2 & 3 & 3 & 1 & 1 \\
\hline $\begin{array}{l}\text { Czech } \\
\text { Republic }\end{array}$ & 2 & 3 & 3 & 1 & 2 & 2 & 3 & 3 \\
\hline Denmark & 1 & 1 & 1 & 3 & $2^{*}$ & $1^{*}$ & 2 & 2 \\
\hline Estonia & 3 & 3 & 3 & 2 & 2 & 2 & 3 & 3 \\
\hline Finland & 2 & 2 & 2 & 3 & 3 & $1^{*}$ & 2 & 2 \\
\hline France & 2 & 1 & 1 & 2 & 2 & 1 & 1 & 1 \\
\hline Germany & 2 & 1 & 1 & 1 & 1 & 1 & 2 & 2 \\
\hline Greece & 2 & 2 & 1 & 2 & 1 & $\mathrm{~N} / \mathrm{A}$ & 2 & 2 \\
\hline Hungary & 3 & 3 & 2 & 2 & 2 & 3 & 3 & 3 \\
\hline Ireland & 1 & 1 & 2 & $3 *$ & 2 & 1 & 1 & 1 \\
\hline Italy & 2 & 2 & 2 & 2 & 1 & 2 & 1 & 1 \\
\hline Latvia & 3 & 3 & 3 & 1 & 2 & 3 & 3 & 3 \\
\hline Lithuania & 3 & 3 & 3 & 1 & 1 & 2 & 3 & 3 \\
\hline Luxembourg & 1 & 1 & 3 & 2 & $3 *$ & $1^{*}$ & 1 & 1 \\
\hline Malta & 1 & 1 & 2 & 3 & 2 & 2 & 2 & 2 \\
\hline Netherlands & 1 & 1 & 1 & 3 & $1 *$ & $1^{*}$ & 1 & 1 \\
\hline Poland & 3 & 3 & 3 & 1 & 3 & 3 & 3 & 3 \\
\hline Portugal & 3 & 2 & 1 & 3 & 1 & 3 & 2 & 2 \\
\hline Romania & 3 & 3 & 3 & 1 & 3 & 3 & 3 & 3 \\
\hline Slovakia & 3 & 3 & 2 & 1 & $3 *$ & 2 & 3 & 3 \\
\hline Slovenia & 2 & 2 & 2 & 2 & 3 & 2 & 2 & 2 \\
\hline Spain & 2 & 2 & 2 & 3 & 2 & 3 & 1 & 1 \\
\hline Sweden & 1 & 1 & 1 & $3 *$ & $1 *$ & $1^{*}$ & 1 & 1 \\
\hline $\begin{array}{l}\text { United } \\
\text { Kingdom }\end{array}$ & 1 & 2 & 2 & 3 & 3 & 1 & 2 & 2 \\
\hline *counis & & & & & & & \\
\hline
\end{tabular}

1 - countries with improved value of an indicator

2 - countries with average value of an indicator

3 - countries with poorer value of an indicator

Fields marked * are based on the latest available statistic data from 2005-2007.

SDR. The values connected with the second economic indicator are slightly higher +0.83 and -0.83 . A weaker dependence can be observed between total health expenditure per capita and total health expenditure as $\%$ of GDP $(+0.65)$. The weakest links were identified while comparing the health care indicators and total health expenditure per capita $(-0.34,+0.15$ and +0.55$)$.

\section{DISCUSSION AND CONCLUSIONS}

Based on the results of the analysis we can conclude that when reflecting all the indicators the Czech Republic balances on the verge of groups of countries with average values or poorer values of indicators. Small exception was noticed in the acute hospital beds per 100,000 inhabitants indicator. When analyzing the Czech 
Table 4. Variables and their correlation

\begin{tabular}{|l|c|}
\hline Variables & Correlation coefficient \\
\hline A.1. vs. A.2. & +0.94 \\
\hline A.1. vs. C.1. & +0.76 \\
\hline A.1. vs. C.2. & -0.76 \\
\hline A.2. vs. A.3. & +0.65 \\
\hline A.2. vs. B.1. & -0.34 \\
\hline A.2. vs. B.2. & +0.15 \\
\hline A.2. vs. B.3. & +0.55 \\
\hline A.2. vs. C.1. & +0.83 \\
\hline A.2. vs. C.2. & -0.83 \\
\hline
\end{tabular}

indicators, an interesting fact appears. A relatively positive trend of changes in life expectancy and SDR in 1995-2008 reference period appears but the same cannot be said for health expenditure. Compared to other countries the development of total health expenditure was less positive despite the slightly above average growth in the GDP per capita. The general observation shows that the countries ranking worse in economic level indicators rank worse also in population health status indicators. These are mostly former Eastern Bloc countries (e.g. Romania, Bulgaria, Latvia, Lithuania, Estonia, Hungary, Poland and Slovakia). At the opposite end of the spectrum are the countries with best values of economic indicators and good values of population health status indicators (e.g. Austria, Ireland, Luxembourg, the Netherlands or Sweden). This suggests that there is a connection between the economic level and health status of population, expressed by the life expectancy. The connection was also additionally confirmed by calculation of the correlation coefficient between variables, where such correlation analysis is used within the framework of simplified modeling of reality by means of chosen indicators. We can note a strong association of health status of population indicators (life expectancy and mortality rate) and either GDP per capita or total health expenditure per capita. A strong relation was also noted between GDP per capita and total health expenditure per capita. On the contrary, there is not any strong association between health care indicators (acute hospital bed per 100,000, physicians and nurses per 100,000) and total health expenditure per capita. In these indicators the developed countries sometimes ranked below average while less developed ones were above average (especially notable in acute beds numbers). This discrepancy can be likely attributed to differences in the set up of the health care systems in different countries and the emphasis that the developed countries put on the efficient spending of their funds (e.g. using new diagnostic methods and therapies that result in shorter hospitalization). This topic could be later extended by including more indicators of health care (e.g. number and age of modern diagnostic and therapeutic devices, the number of preventive visits, number of operations and other medical interventions). This could be prevented by lack of complete and comparable statistic data. Future studies of the abovementioned associations within the Czech health care system should focus on lower regional level and may thus provide more detail information for future development. Beside the issues of identification and use of other indicators for future study of the given problems, there is also a possibility to use more advanced statistical methods and procedures in the next surveys, which would eliminate some drawbacks and methodological limits perceived by the authors in respect of the methods chosen within the framework of the presented paper (e.g. supplementing the calculation of correlations with multiple regression analysis, or reduction of inappropriate indicators by means of exploratory factor analysis).

\section{Acknowledgements}

The authors are thankful to the Internal Grant Agency of the Ministry of Health of the Czech Republic for the grant no. NT12235 - "Application of Modern Calculation Methods for Costs Optimization in Health Care" which provided financial support for this survey.

\section{REFERENCES}

1. Catalano R, Frank J. Detecting the effect of medical care on mortality. J Clin Epidemiol. 2001 Aug;54(8):830-6.

2. Mechanic D, Rochefort DA. Comparative medical systems. Annu Rev Sociol. 1996;22:239-70.

3. Smith DW, Bradshaw BS. Variation in life expectancy during the twentieth century in the United States. Demography. 2006 Nov;43(4):647-57.

4. Kindig DA. Purchasing population health: aligning financial incentives to improve health outcomes. Nurs Outlook. 1999 Jan-Feb;47(1):15-22.

5. Bunker JP. The role of medical care in contributing to health improvements within societies. Int J Epidemiol. 2001 Dec;30(6):1260-3.

6. Cutler DM, Rosen AB, Vijan S. The value of medical spending in the United States, 1960-2000. N Engl J Med. 2006 Aug 31;355(9):920-7.

7. McKee M. What can health services contribute to the reduction of inequalities in health? Scand J Public Health Suppl. 2002;59:54-8.

8. Ginter E, Simko V. Health differences between populations of the United States of America and the European Union. Cent Eur J Public Health. 2010 Dec;18(4):215-8.

9. Kindig DA, Seplaki CL, Libby DL. Death rate variation in US subpopulations. Bull World Health Organ. 2002;80(1):9-15.

10. Horev T, Pesis-Katz I, Mukamel DB. Trends in geographic disparities in allocation of health care resources in the US. Health Policy. 2004 May;68(2):223-32.

11. Blakely T, Ajwani S, Robson B, Tobias M, Bonné M. Decades of disparity: widening ethnic mortality gaps from 1980 to 1999. N Z Med J. 2004 Aug 6;117(1199):U995.

12. Babazono A, Hillman AL. A comparison of international health outcomes and health care spending. Int $\mathrm{J}$ Technol Assess Health Care. 1994; 10(3):376-81.

13. Skinner J, Chandra A, Goodman D, Fisher ES. The elusive connection between health care spending and quality. Health Aff (Millwood). 2009 Jan-Feb;28(1):w119-23.

14. Aaron HJ, Ginsburg PB. Is health spending excessive? If so, what can we do about it? Health Aff (Millwood). 2009 Sep-Oct;28(5):1260-75.

15. Gulliford MC, Jack RH, Adams G, Ukoumunne OC. Availability and structure of primary medical care services and population health and health care indicators in England. BMC Health Serv Res. 2004 Jun $11 ; 4(1): 12$.

16. Gu D, Zhang Z, Zeng Y. Access to healthcare services makes a difference in healthy longevity among older Chinese adults. Soc Sci Med. 2009 Jan;68(2):210-9.

17. Alonso J, Orfila F, Ruigómez A, Ferrer M, Antó JM. Unmet health care needs and mortality among Spanish elderly. Am J Public Health. 1997 Mar;87(3):365-70.

18. Ginter E, Simko V, Wsolova L. Fall of the iron curtain: male life expectancy in Slovakia, in the Czech Republic and in Europe. Cent Eur J Public Health. 2009 Dec;17(4):171-4.

19. Eriksen BO, Kristiansen IS, Nord E, Pape JF, Almdahl SM, Hensrud A, et al. Does admission to a medical department improve patient life expectancy? J Clin Epidemiol. 1997 Sep;50(9):987-95.

20. Bunker JP, Frazier HS, Mosteller F. Improving health: measuring effects of medical care. Milbank Q. 1994;72(2):225-58.

21. Rodwin VG. Expenditure on health care services and population health. Seve: les tribunes de la Sante. 2010 September;Hors Serie:31-6. 
22. Marmot M. Social determinants of health inequalities. Lancet. $2005 \mathrm{Mar}$ 19-25;365(9464):1099-104

23. Gu D, Sautter J, Huang C, Zeng Y. Health inputs and cumulative health deficits among the older Chinese. Soc Sci Med. 2011 Mar;72(5):806-14.

24. Wilson K, Eyles J, Elliott S, Keller-Olaman S. Health in Hamilton neighbourhoods: exploring the determinants of health at the local level. Health Place. 2009 Mar;15(1):374-82.

25. Bobak M, Pikhart H, Rose R, Hertzman C, Marmot M. Socioeconomic factors, material inequalities, and perceived control in self-rated health: cross-sectional data from seven post-communist countries. Soc Sci Med. 2000 Nov;51(9):1343-50.

26. Černá M, Spěváčková V, Batáriová A, Šmíd J, Čejchanová M, Očadlíková D, et al. Human biomonitoring system in the Czech Republic. Int J Hyg Environ Health. 2007 May;210(3-4):495-9.

27. Bencko V, Černá M, Jech L, Šmíd J. Exposure of breast-fed children in the Czech Republic to PCDDs, PCDFs, and dioxin-like PCBs. Environ Toxicol Pharmacol. 2004 Nov;18(2):83-90.

28. Bencko V, Holcátová I, Novotný L, Rameš J, Slámová A. The primary prevention - the health protection yesterday, today and tomorrow. Živ Prostr. 2002;36(3):120-3. (In Slovak.)

29. Cikrt M, Pelclová D, Markvart K, Lukáš E, Kř́ž J. Occupational and environmental medicine in Czech Republic. Int Arch Occup Environ Health. 1997;69(2):79-82.
30. Adams P, Hurd MD, McFadden D, Merrill A, Ribeiro T. Healthy, wealthy, and wise? Tests for direct causal paths between health and socioeconomic status. Journal of Econometrics. 2003 Jan;112(1):3-56.

31. Bauer G, Davies JK, Pelikan J. The EUHPID Health Development Mode for the classification of public health indicators. Health Promot Int. 2006 Jun;21(2):153-9.

32. Möller J, Laaser U, Güntert B. Evaluation of health care systems: contributions made by "the WHO world health report 2000". Z Gesundh Wiss. 2002;10(4):316-25.

33. Navarro V, Muntaner C, Borrell C, Benach J, Quiroga A, RodríguezSanz M, et al. Politics and health outcomes. Lancet. 2006 Sep 16;368(9540):1033-7.

34. European Health for All Database HFA-DB [Internet].Copenhagen: WHO Regional Office for Europe; c2011 [cited 2011 Jun 2]. Available from: http://data.euro.who.int/hfadb/.

35. European Commission. Statistics database [Internet]. Luxembourg: Eurostat [cited 2011 Jun 2]. Available from: http://epp.eurostat.ec.europa. eu/portal/page/portal/statistics/search_database.

Received July 22, 2011

Accepted in revised form March 1, 2012 